\title{
A Comparative Analysis of Intonation Between Spanish and English Speakers in Tag Questions, Wh-Questions, Inverted Questions, and Repetition Questions
}

\author{
Uma análise comparativa de entonação \\ entre falantes de espanhol e inglês em tag \\ questions, Wh-questions, perguntas \\ invertidas e perguntas de repetição
}

Maria Gabriela Valenzuela Farías*

Universidad Católica de la Santísima Concepción (UCSC)

Concepción - Chile

ABSTRACT: The aim of this study was to determine the differences and similarities in intonation when producing tag questions, wh-questions, inverted questions, and repetition questions among native English speakers and ESL Spanish speakers. These differences were measured and analyzed with a computer program called Praat, and the pitch, the intensity and the intonation contour were the focus of the study. The results have shown significant differences, as well as similarities between these two languages in some questions. The implication of this study is that the obtained data can help teachers and students to identify the problems that ESL Spanish speakers can have when learning English as a L2, especially with regards to intonation.

KEYWORDS: Spanish intonation; English intonation; pronunciation; pitch; intensity.

RESUMO: O objetivo deste estudo foi determinar as diferenças e semelhanças na entonação ao produzirem-se tag questions, Wh-questions, perguntas invertidas e perguntas de repetição entre falantes nativos do inglês e falantes do espanhol ESL. Essas diferenças foram medidas e analisadas com um programa de computador chamado Praat. Os resultados mostraram diferenças significativas, assim como semelhanças entre essas duas línguas. A implicação deste estudo é que os dados obtidos podem ajudar professores e alunos a identificar os problemas que os falantes de espanhol ESL podem ter ao aprender inglês como L2, especialmente em relação à entonação.

PALAVRAS-CHAVE: entonação; espanhol; entonação inglês, pronúncia, pitch, intensidade.

* gabrielavale@gmail.com 
The purpose of the study is to compare the intonation in acts of speech and interrogative sentences between native English speakers and Spanish speakers speaking English as their second language, to predict possible problems in communication on account of their intonation.

Intonation plays an important role in learning a second language, but unfortunately comparatively little attention has been given to this issue in ESL instruction. Intonation is not only related to the rhythm of the language, but also it is deeply connected to how attitudes and emotions are expressed during the act of speech. It is a "powerful tool in the message of any linguistic exchange” (RAMIREZ VERDUGO, 2006).

I believe that intonation is essential in second language learning. To avoid an L2 speaker being misunderstood, it must be integrated into the curriculum of any second language instruction to help students understand the prosodic features of the new language.

L1 intonation is learned in the first stage of language acquisition and becomes automatic after this period. Because of this, second language speakers will generalize L1 intonation rules over the L2 language, opening possibilities for miscommunication or sometimes unintelligibility (RAMIREZ VERDUGO, 2006).

Another theory explains that non-native speakers can develop (in early stages) two linguistic systems that can influence the production of sounds and intonation, which does not necessarily mean an automatic negative transfer into the L2, but it is still a difference between L1 and L2 that can create a new form of intonation (FLEGE, 1987).

For Spanish speakers, the issue of intonation is essential to avoid a "flat sound" (CELCIE-MURCIA; BRINTON; GOODWIN, 1996) due to the fact that Spanish intonation has different pitch movements and language learners tend to transfer the $\mathrm{L} 1$ intonation contours. The most frequent error for Spanish speaker is to generalize the falling English contour without noticing the pragmatic use of it. Second language learners need to know the different prosodic elements in English, so they can understand them, and later on generate the appropriate utterance, depending on the meaning that the speech is intended for (RAMIREZ VERDUGO, 2006).

The aim of this study is to determine the differences in intonation while producing tag questions, wh-questions, inverted questions and repetition questions among native English speakers and ESL Hispanic speakers. These differences will be measured and analyzed with a computer program called Praat, which has been recently used to help students perceive and improve their L2 pronunciation. 


\section{Literature Review}

\section{Intonation}

Wennerstrom (2001) referred to intonation as the melody created by the voice while producing a speech, giving the opportunity to the speaker to choose their pitch according to what he/she wants to express in his/her utterance.

Levis (1999) referred to Allen's (1971) work to state that intonation is the rhythm and the melody of the language that includes stress, volume and pauses. In his definition, Levis argued that intonation is not only prosody but also voice quality and intensity. In his work, Levis also referred to Ladd's (1996) work to illustrate that intonation is defined as the different ways in which the pitch of an utterance can function at discourse level (rising-falling final pitch).

Crystal (1969, as cited in JOHNS-LEWIS, 1986) noted that intonation is a complex concept that usually covers several prosodic systems such as pitch, tone, tempo, rhythm and loudness. Wennerstrom (2001) divided intonation into four categories: pitch accents, pitch boundaries, key, and paratones. Pitch accents refer to the different kinds of tones that will be used by the speaker; in other words, it is the stress of the pronounced word.

Pitch boundaries, on the other hand, refer to the lengthening of the ending of the word or utterance, also identified as rising or falling intonation. Key indicates the attitude of the speaker towards a previous utterance. High key indicates contrast response while mid key indicates neutral, and low key refers to not having new information for uttering a response. Finally, paratones represent the narrowness or wideness of the pitch range.

Ramirez Verdugo (2005) referred to Halliday's (1994) work to argue that intonation can be divided into three important systems: tonality, tonicity and tone. Tonality is the scheme that divides speech into intonational units. Tone indicates the different pitch movements of intonation, besides expressing personal metafunctions; and tonicity represents textual metafunctions.

According to Ramirez Verdugo (2005), tone is essential to comprehend the statement given in an utterance such as questions or commands. Ramirez agreed with Wennerstrom (2001) about the importance of the key to understand speakers' attitude towards a specific topic. However, Ramirez discussed and added the term modality. Modality is responsible for evaluating how certain or uncertain the spoken utterance is. 
Another important point to be mentioned is the fact that in English, there are distinct intonational phrases. According to Ladefoged (2006), the changes produced in a sentence due to different levels of pitch are shown in an intonational phrase. This phrase is often noticeable because of a tonic syllable which shows the strongest point in pitch's change. The tonic syllable occurs whenever a word needs to be emphasized.

Intonational phrases point toward the intention of the speakers, and tonic syllables usually show new information or ideas that the speaker wants the listener to pay attention to.

According to what has been discussed above, it can be concluded that the awareness of English intonation will empower students to avoid miscommunication, because the proper intonation helps communicate the message more accurately.

\section{A comparison of English and Spanish intonation}

Pitch is an essential component in English intonation. It is responsible for letting the listener know the intention of the speaker in a conversation. In English Pitch is divided into low, mid and high intensity. The pitch of a spoken word determines the direction (rising or falling) and the stress of the utterance.

Low, mid, and high pitch usually represent different intentions in the speech act. For example, a common surprise sentence will result in an utterance with a high pitch level. However, a rising pitch will indicate a question and a lower pitch can be used for giving commands.

According to Spaii and Hermes (1993), pitch variations are essential components not only to distinguish the speaker's intention, but also to identify non-linguistic tasks such as emotions, social status, and personalities. He also argued that pitch and intonation are involved and represent more than just pragmatics; they also help for comprehension and carry grammatical functions.

Most of the time for non-native speakers of English (and, in this case, focusing specifically on Spanish speakers), not being aware of the different kinds of pitch in the speech acts can lead to misunderstood information, leading the listener to perceive spoken words in a very different way from the real intention of the speaker. Since Spanish is a language with a narrow variation in intonation, ESL learners may tend to transfer their pitch into English, having as a result a "flat" sound (CELCE-MURCIA et al., 1996.) These idiosyncrasies can affect the way a Spanish speaker perceives and applies intonation rules while speaking English. 
According to Bowen (1956), Spanish intonation has two kinds of stress (weak and strong) three terminal junctures (rising, falling, sustained), and finally three different kinds of pitch levels (low-1, mid-2, high-3). Bowen compared the differences in intonation between Spanish and English. He discovered that Spanish changes pitch in the strong stressed syllable, or in the first or last weak stressed syllable of a sentence. According to Bowen, Spanish speakers reading utterances in English negatively transfer L1 intonation patterns, for example, a Spanish emphatic sentence, such as "he does eat pasta" (el sí come pasta) to an English speaker is perceived as annoying one. This is attributed to negative intonation transfers. The same effect occurs if an English speaker speaks the same sentences, transferring English intonation into Spanish utterances. Usually in emphatic sentences the pitch level in English is too high in comparison with Spanish emphatic utterances.

Moreover, in yes or no questions, Bowen (1956) discovered that the Hispanic's perception of English sentences also suffered some distortion. In Spanish, yes or no questions end with a high-level pitch. If the speaker produces the same sentence in English, it sounds like an over-emphatic question (because of transferring L1intonation to L2). In his work, Bowen discussed the importance of helping students to be aware of the main differences in intonation between languages in order to avoid miscommunication. When students do not have the opportunity to interact with native speakers, they do not get the chance to receive native-like input. Therefore, they do not have the chance to achieve full proficiency in the intonation of L2.

Graham (1978) argued that even though Spanish and English do share certain intonation patterns such as a rising pitch at the end of questions, these two languages also share several dissimilarities. According to Graham, English has four different pitches and Spanish has three, lacking the last extra-high pitch that English possesses and which usually indicates enthusiasm and happiness, for example:

(1) Anda (low) He is walking (low)

(2) ¡Anda! (middle) Walk! (middle)

(3) ¡Anda! (high) Good heavens! ( high)

(4) Anda? Is he walking? (extra-high) 
The lack of the fourth extra-high pitch in Spanish makes the emphatic intonation in Spanish sound like a normal simple statement in English, creating the perception of a "flat" sound for English listener; however, for a Spanish listener this extra-high pitch produced by the English speaker will result in an over exaggerated sound.

Chela-Flores and Chela-Flores (2003) argued and agreed with Graham (1978) about the similarities between Spanish and English pitch movements in questions with raising intonation, such as Qué? What? However, ChelaFlores and Chela-Flores stated that Spanish as well as English has four pitch levels; the significant difference is the meaning and the importance that these four high pitches have in both languages.

According to Chela-Flores and Chela-Flores (2003), Spanish learners of English cannot notice and therefore have problems in understanding how the four high pitch levels work in English. As a result, they have difficulties in producing pitch changes when they need to go from a level three high pitch to a level four high pitch to make a distinction between simple declaratives sentences and emphatic sentences.

In addition, Graham (1978) argued that it is important to realize the differences between pitches not only in statements but in questions as well. According to Graham, English questions are extremely flexible, so intonation will play an essential role during the placement of the stress for emphasizing meaning. However, in Spanish questions this flexibility on intonation does not play that important a role. Spanish speakers will change the sentence order or add new words to express different meanings instead of playing with the stress of the words. For example:

(1) Would you like tea or coffee? (or wouldn't you)/ Quieres té or café, si o no?

(2) Would you like tea or coffee? (specifically you) / Tú quieres té or café?

(3) Would you like tea or coffee..? (maybe something else)/ Quieres té, café u otra cosa?

Chela-Flores and Chela-Flores (2003) agreed with Graham (1978) remarking the importance of the word order or the addition of new words in Spanish to emphasize new or important information, and in the use of stress and pitch changes in English to signal relevance in a sentence. The only different argument added to Graham's claims is the fact that for Spanish speakers, the distinction and later on the application of pitch shifting in English sentences without obtaining erroneous utterances is difficult. For example: 
Did you call him? / lo llamaste tú?

Did you call him?/ tú lo llamaste a él?

Awareness of L1 and L2 intonations is essential for mastering a second language. Not having the correct knowledge can lead to several problems such as general misunderstandings while producing L2 utterances, even though L1 and L2 share similar characteristics such as in the case of English and Spanish.

\section{Visual technology, Praat}

Visual technology has been used to see the different patterns of intonation between English and others languages. Since the 1960s, it has become a powerful tool among some researchers and second language teachers for investigating intonation and other suprasegmental features to help second language learners adapt and improve their pronunciation. It also helps them to realize that there are significant differences between languages that can affect the goal of understandable communication. Visual technology is not a widelyused instrument; it is gaining more importance among people who believe that the backbone of second language learning is pronunciation. This trend is shifting the belief that suprasegmentals are not extremely important in the acquisition of a second language.

Praat is a speech analysis computer program that was developed by the Phonetics Department at the University of Amsterdam under the direction of Boersma and Weenink (2008). Within its multiple features, Praat can produce spectrogram analysis, pitch analysis, formant analysis, and intensity analysis, among others. This new program provides exact and clear results while measuring different intonation patterns.

The pitch contour that is shown by the program can be divided into three parts: minimum pitch, maximum pitch, and average pitch. Moreover, intensity and frequency are also reflected in the spectrogram highlighted by different colors, making the comprehension of these two elements clear for the observer.

There are multiples functions that can be obtained by using this program but, for the purpose of this study, I will just consider the use of pitch and intensity, because in the case of pitch it will show intonation contours, and the intensity will indicate the place and force where the stress is put in the sentences. 
In conclusion, it is important to understand that English and Spanish, even though they do share similar characteristics, also have important dissimilarities such as duration and pitch. Therefore, awareness of phonetics differences between these two languages is important for teachers and second language learners.

In the following section I will discuss the methodology of the present study which will be followed by the discussion of the results. Subsequently, I will state the conclusions to finalize with the limitations of this research.

\section{Methodology/procedures}

This study will address the following research questions:

(1) What are the similarities and differences between English and Spanish intonation in wh-questions, tag questions, inverted and repetition questions?

(2) How to go about measuring both similarities and differences?

\section{Participants}

The participants were six male literate native English speakers between the ages of 20 and 25 from the metro area in Minnesota, and six literate Spanish speakers between the ages of 20 and 25 from different Spanish speaking countries which were randomly chosen according to the accessibility of SCSU students (Chile, Venezuela, Peru, and Ecuador). The participants were current undergraduate St. Cloud State University (SCSU) students with an advanced proficiency level of English. None of the participants had taken previous pronunciation classes and all of them have lived and studied at least 2 years in the United States.

\section{Materials}

The materials used in this research were a set of three tag questions, three inverted questions, three wh-questions and three repetition questions. These questions were taken from Celce-Murcia et al.'s (1996) book, Teaching Pronunciation. Also, the same set of questions were translated into Spanish and read by the Spanish speakers' students in their L1. These particular questions were chosen to see if the results that Celce-Murciass book showed as examples were useful with Spanish speakers. Some sample questions in English were: It is a nice day, isn't it? John cooked dinner? What are you doing? What am I doing? The Spanish sample 
versions were: ¿¿Es un bonito día, cierto?, ¿John preparó la cena?, ¿Qué haces?, ¿Qué tengo que hacer yo? (see appendix)

\section{Procedures/Data Collection}

In order to show the differences in intonation the questions previously mentioned were given to six native English speakers for them to read without practicing prior to the recording. The same sets of questions were given to the Spanish speakers to read without time to practice prior to the recording. The Spanish speakers also were asked to read the same questions but in their native language, they had a total of 24 questions to read.

To record and analyze participants' intonation, the program Praat was used as the visual technology support. This program shows, after recording a sentence, a screen with the pitch contour of the uttered sentence, besides giving the pitch, the intensity and its duration.

After getting the minimum and maximum pitch of each sentence (24 in total), the mean of these two values was calculated. Then, the average result of each participant was taken into account to calculate the standard pitch that was used to draw the final conclusions. The same procedure was done in order to obtain the intensity. The fact that individual differences are present was taken into account in order to analyze and compare results among participants (LADEFOGED, 2001).

The samples were recorded at Saint Cloud State University, in the Mass Communication Department's soundproof room.

\section{The findings/discussion}

\section{Wh-questions}

According to Celce-Murcia et al., (1996), wh-questions contain risingfalling intonation especially when they are unmarked. In order to observe this claim, the set of questions that participants read were taken from the examples given by this author. (see appendix)

Example: what are you DQing?

Similarities: The comparison between native speakers of American English and native speakers of Spanish reading sentences in English were the following: 
The results indicate that $100 \%$ of the participants who were native English speakers ended the questions with a falling contour, and $66 \%$ of the Spanish speakers followed the same tendency. The following figures will show an example of how the Praat's screens were obtained during the research (see figures 1,2).

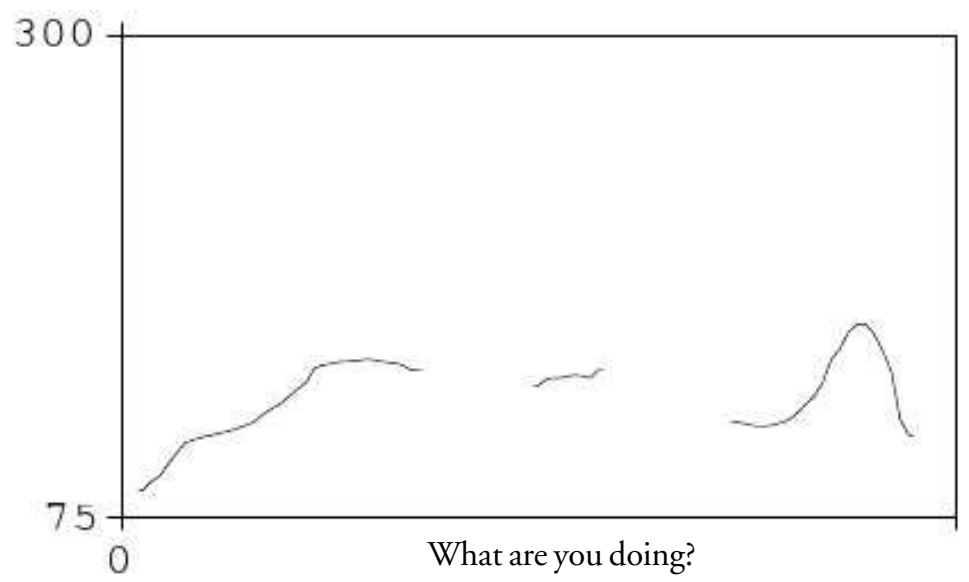

FIGURE 1. Example of the pitch contour of a wh-question produced by an English speaker reading a sentence in English

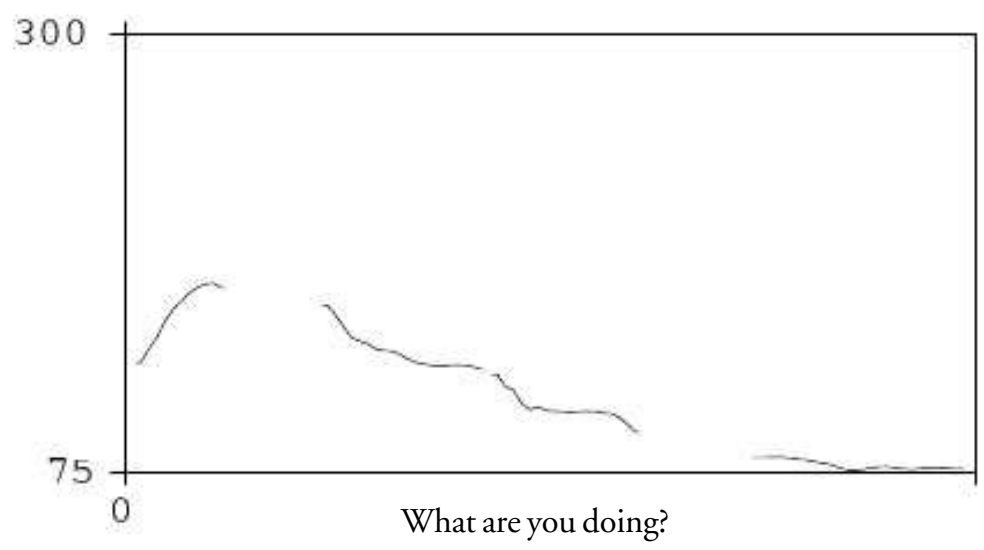

FIGURE 2. Example of a pitch contour of a wh-question produced by a Spanish speaker reading an English sentence

Differences: The main difference obtained, after comparing the data for wh-questions, was the mean pitch. The average pitch for native English speakers was $135 \mathrm{~Hz}$, which highly contrasted with the $180 \mathrm{~Hz}$ as standard 
pitch for Spanish speakers when producing English sentences. In the case of Spanish sentences, the average pitch was $143 \mathrm{~Hz}$; this result shows that Spanish speakers made important changes while uttering sentences in each language (English and Spanish). It is important to notice that when Hispanic participants read the sentences in their own language (Spanish), a marginal difference among speakers in the average pitch was obtained.

TABLE 1

Mean of WH-Questions

\begin{tabular}{l|c|c|c}
\hline Participants & Sentences & Mean pitch & Intensity average \\
\hline Spanish & English & $180 \mathrm{~Hz}$ & $73 \mathrm{db}$ \\
\hline English & English & $135 \mathrm{~Hz}$ & $75 \mathrm{db}$ \\
\hline Spanish & Spanish & $143 \mathrm{~Hz}$ & $70 \mathrm{db}$ \\
\hline
\end{tabular}

Another important difference to highlight is that Spanish wh-questions produced by the participants had the tendency to end with rising intonation, as opposed to the falling contour given by the Spanish speakers to English sentences. This shows that Spanish speakers have mastered English whquestions. Therefore, it might be observed that there is no negative transfer from Spanish, which can be attributed to the fact that wh-questions in Spanish, according to Lee (2004), have a tendency to rise on the final syllable. A sample of how the pitch contour was seen during the production of Spanish sentences is the following (see figure 3).

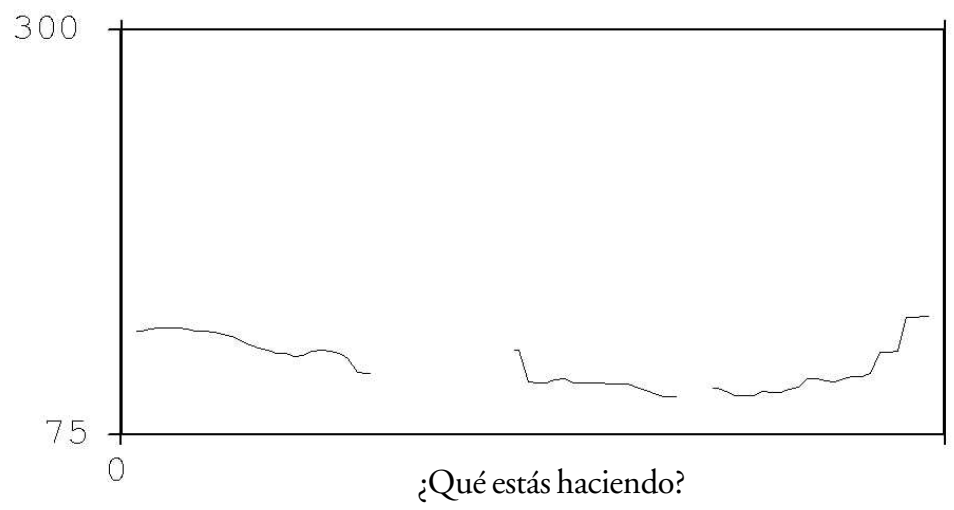

FIGURE 3. Sample of a Pitch contour obtained from a Spanish speaker reading a Spanish wh-question 
The comparison of the two figures (see figure 1 and 2) shows that in wh-questions, Spanish speakers reading in English end their sentences with falling contour even though they produce a higher pitch at the beginning. The average of the English speakers' sentence shows that they ended the sentence with a falling contour as well, although there are more noticeable rising and falling pitches variations during the production of the sentences. The similarities presented in the final contours among these two languages show that Spanish speakers did not transfer their L1 intonation into L2. Moreover, the general production of Spanish wh-questions shows (see figure 3) that the tendency is to rise at the end of the sentence.

\section{Tag questions}

According to Celce-Murcia et. al. (1996), the typical and most common use of tag questions in English is for clarifying information, and the falling ending contour is used frequently with that purpose. However, a rising contour is also utilized when tag questions are used as a yes/no ones.

Examples: It's a nice DAY, ISn't it? The Dodgers WQN, DIDn't they?

The following results were obtained for pitch, intensity and final contour:

Similarities: The results show that $66 \%$ of the native English speakers ended their questions with rising intonation giving them an average meaning of yes/no questions to the sentences, and not a purpose of clarification. As an example of how the pitch contour was shown in Praat's screen are the following figures (see figures 4, 5, 6).

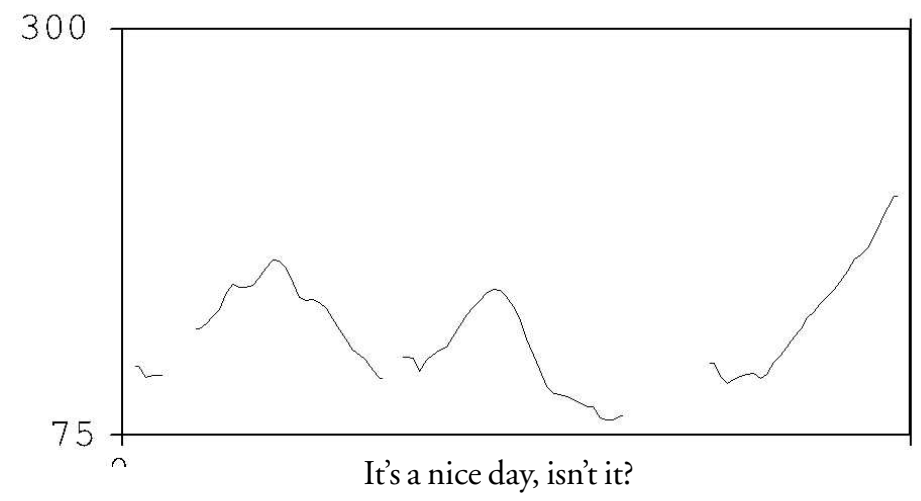

FIGURE 4. Example of an English speaker's tendency reading a tag question in English 
Furthermore, 83\% of English sentences read by Spanish speakers ended with rising intonation, showing the possibility that speakers used these questions as yes or no ones, just as the English native speakers did. While reading Spanish sentences, $88 \%$ of the participants ended with rising final contours, maintaining the tendency of the Spanish tag questions' endings (LEE, 2004).

The comparison between Spanish sentences (see figure 6 as model) and the English sentences produced by Spanish speakers (see figure 5 as example) show that both ended with rising intonation. Although the pitch variations during the production of the sentences are not exactly the same, they are similar.

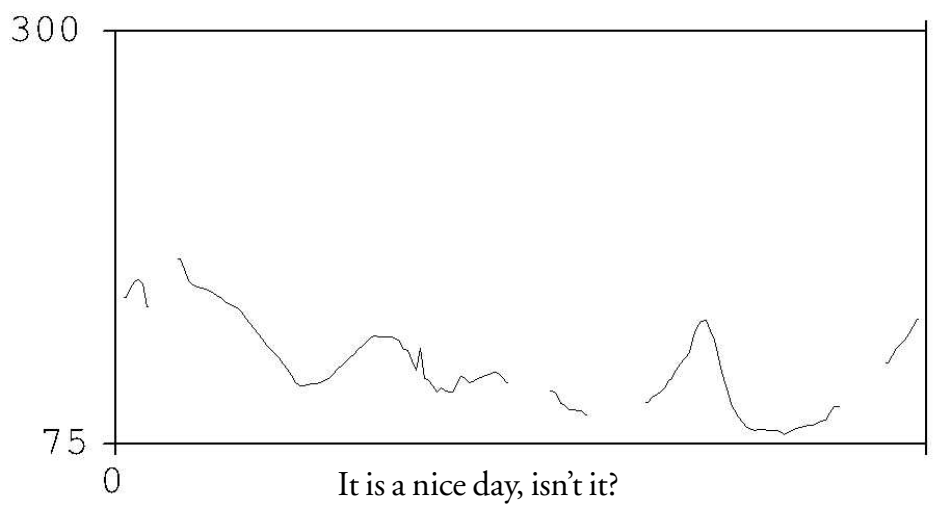

FIGURE 5. Sample of the pitch contour produced by a Spanish speaker reading a tag question in English

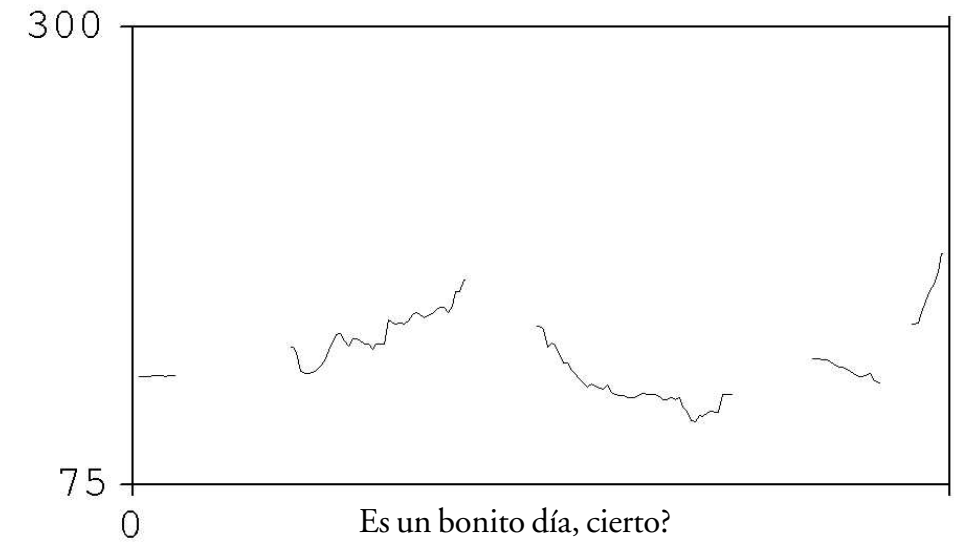

FIGURE 6. Illustration of the pitch contour produced by a Spanish speaker reading a Spanish tag question 
Another similarity observed was in average pitch. The average pitch for tag questions for native English speakers was $128 \mathrm{~Hz}$, very similar to their Spanish speaking counterparts, which registered a standard pitch of $130 \mathrm{~Hz}$ in English questions, and $133 \mathrm{~Hz}$ in Spanish questions. The average intensity produced by Spanish speakers in both languages was the same; a slight difference was noticeable when comparing it with the English speakers' intensity.

TABLE 2

Mean results of TAG Questions

\begin{tabular}{l|c|c|c}
\hline Participants & Sentences & Mean pitch & Intensity average \\
\hline Spanish & English & $130 \mathrm{~Hz}$ & $69 \mathrm{db}$ \\
\hline English & English & $128 \mathrm{~Hz}$ & $74 \mathrm{db}$ \\
\hline Spanish & Spanish & $133 \mathrm{~Hz}$ & $69 \mathrm{db}$ \\
\hline
\end{tabular}

Differences: no differences were found.

\section{Inverted questions}

The purpose of this kind of sentence is to show expectation or impatience, and the focus of the sentence is indicated by the stress and high pitch produced by the speaker. The general tendency is to end with rising intonation (CELCIA-MURCIA et al., 1996).

Examples : JOHN cooked dinner? (focus on John)

John cooked DINner? (focus on dinner)

Similarities: In $72 \%$ of the cases, for Native American English speakers inverted questions ended with a rising intonation. This is similar to the intonation observed in yes/no questions. Spanish speakers had $61 \%$ of the English sentences ending with rising intonation. Even though there are dissimilarities in the percentages, both groups produced more than $50 \%$ of the sentences with a rising ending. The following figures show an example of the images obtained during the recording sessions by the program Praat. 


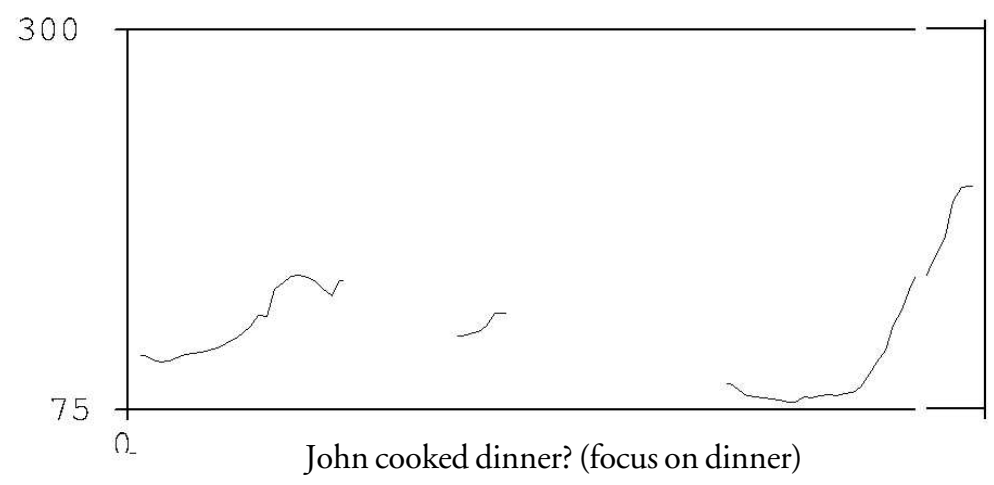

FIGURE 7. Sample of an inverted question in English read by a native English speaker

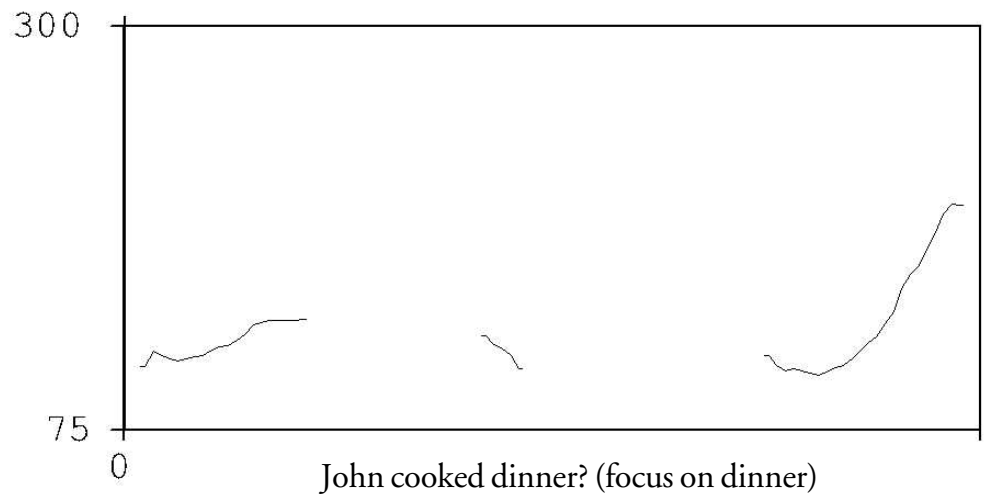

FIGURE 8. A Spanish speaker tendency for an English inverted question

The average intensity for these sentences in the two languages was similar, $72 \mathrm{db}$ for English speakers, $71 \mathrm{db}$ obtained by Spanish subjects reading English sentences, and $69 \mathrm{db}$ for Spanish sentences. Also the mean pitch between English sentences produced by English speakers was alike to the Spanish sentences read by Spanish speakers $126 \mathrm{~Hz}$ and $128 \mathrm{~Hz}$ for the latter language.

TABLE 3

Mean results of inverted questions

\begin{tabular}{l|c|c|c}
\hline Participants & Sentences & Mean pitch & Intensity average \\
\hline Spanish & English & $138 \mathrm{~Hz}$ & $71 \mathrm{db}$ \\
\hline English & English & $126 \mathrm{~Hz}$ & $72 \mathrm{db}$ \\
\hline Spanish & Spanish & $128 \mathrm{~Hz}$ & $69 \mathrm{db}$ \\
\hline
\end{tabular}


Differences: the mean pitch between English speakers and Spanish ones reading English sentences was $126 \mathrm{~Hz}$ for the Anglophones, and $138 \mathrm{~Hz}$ for the Spanish subjects. The latter used a lower pitch similar to English speakers while reading sentences in their own language.

Another important difference to draw attention to is that Spanish speakers, when reading Spanish sentences, had a tendency towards ending them with falling contours, and they shifted to rising final intonation while reading English questions. One possible explanation for this inclination is that in order to express irony, surprise or puzzlement, Spanish speakers chose falling intonation at the end of the sentences (ESCANDELL-VIDAL, 1998). The change of final intonation produced by the participants could indicate that they recognize a difference in the English language. The following figure exemplifies the Praat's screenshots obtained, which support what has been stated previously:

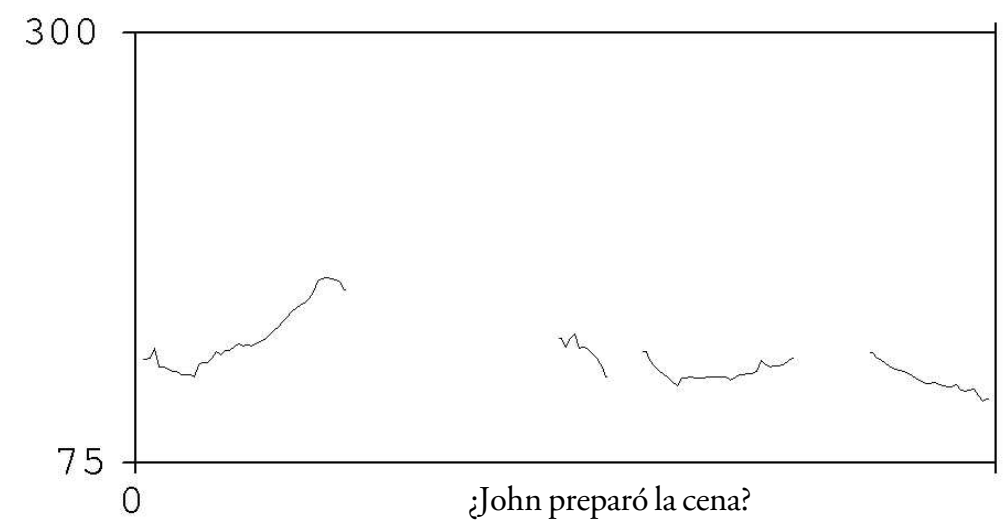

FIGURE 9. Example of the pitch contour produced by a Spanish speaker reading a Spanish inverted question

The average result for inverted questions shows that English speakers and Hispanic speakers employ similar intonation strategies. Inverted questions end with rising intonation in both groups. The real difference here is in the pitch contour. Pitch rises fairly significantly for English speakers but it only rises moderately for Spanish speakers.

The comparison between Spanish sentences and English sentences read by Spanish speakers show a different tendency in pitch contour. Spanish speakers finished the questions with falling intonation in contrast to the production obtained in English questions. 
This general result shows that no negative transfer is evident. On the contrary, Spanish speakers do not produce these sentences with a typical Spanish intonation, which has a downward drift. Consequently, it can be argued that the L2 Spanish learners have acquired the English intonation pattern for these types of sentences.

\section{Repetition questions}

The most common ending for these kinds of questions is the rising one, and the stress of the sentence is mostly placed either at the end or at the beginning of the question (CELCE-MURCIA et al., 1996.) for example:

\section{What am I DO'ing? You are doing ... WHAT?}

Similarities: In this test, $72 \%$ of English sentences read by native English speakers ended with rising intonation; $67 \%$ of Spanish speakers ended English sentences with rising intonation; and $78 \%$ of the Spanish sentences also ended with a raising intonation.

It is important to mention that the percentage of Spanish sentences with rising intonation is higher than the English one even though they were read by the same people; one possible explanation is that, according to Escandell-vidal (1998), repetition questions in Spanish follow the same kind of intonation as yes/no questions, which is mostly a rising ending. The fact that there is not a $100 \%$ agreement among speakers, neither of English nor of Spanish, is because many internal or external factors can influence the utterance of a sentence.

The next figures will show an example of the pictures produced by the computer program while participants were reading their different sentences 


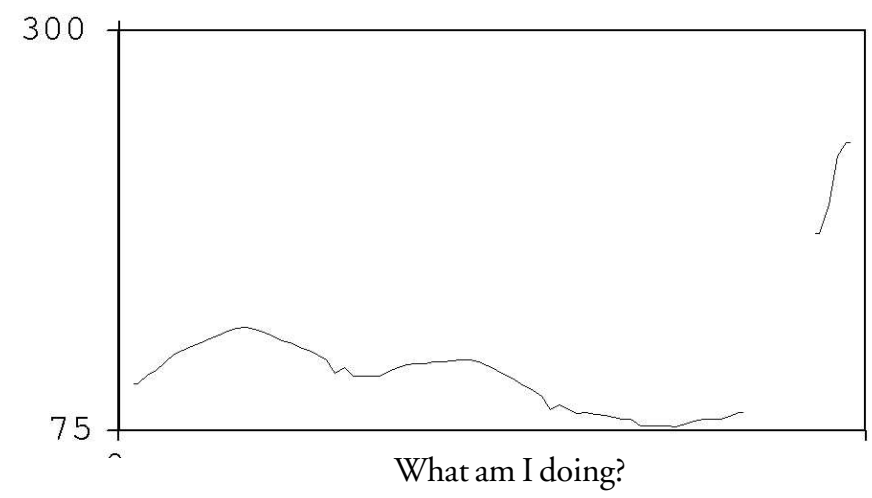

FIGURE 10. Illustration of the pitch contour for an English speaker reading a repetition question in English

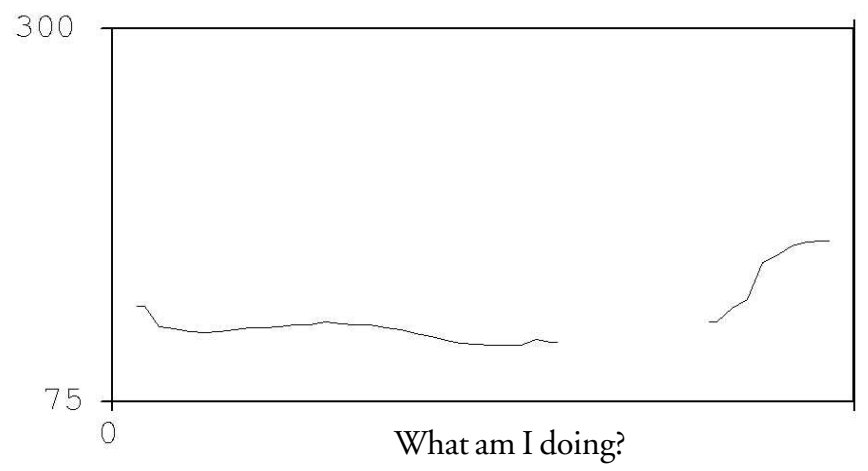

FIGURE 11. Example of the pitch contour produced by a Spanish speaker reading an English repetition question

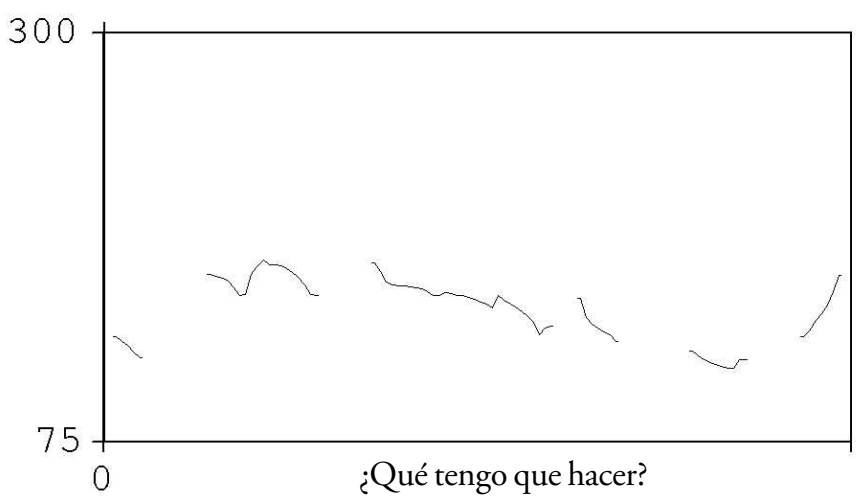

FIGURE 12. Sample of the pitch contour for a Spanish repetition question read by a Spanish speaker 
The average pitch of native English speakers was equivalent to the average of Spanish speakers reading English sentences; in both cases the result was $132 \mathrm{~Hz}$. However, the standard pitch for Spanish sentences was $144 \mathrm{~Hz}$. According to Lindh (2006), this dissimilarity becomes important when it is over $20 \mathrm{~Hz}$. Therefore, for the purpose of this study it will be considered as a marginal difference since the disparity is only $12 \mathrm{~Hz}$.

\section{TABLE 4}

Mean results of repetition questions

\begin{tabular}{l|c|c|c}
\hline Participants & Sentences & Mean pitch & Intensity average \\
\hline Spanish & English & $132 \mathrm{~Hz}$ & $69 \mathrm{db}$ \\
\hline English & English & $132 \mathrm{~Hz}$ & $74 \mathrm{db}$ \\
\hline Spanish & Spanish & $144 \mathrm{~Hz}$ & $68 \mathrm{db}$ \\
\hline
\end{tabular}

Differences: no differences were found.

The average production of repetition questions shows the tendency for both groups to finish the sentence with a rising intonation. In the case of Spanish speakers, this might be due to the fact that the subjects positively transferred their L1 intonation into the L2. It is possible to notice that Spanish speakers, reading in English, tend to maintain a similar pitch up to the end of the question, thus giving the Spanish intonation a "flat" pattern as noted earlier, and can show some evidence for possible transfer. Also the pitch's rise, even though it is high, is dissimilar from the native English speakers but similar to the Spanish sentence. English speakers produced more pitch variations during the sentence and on average; they had a significantly higher pitch towards the end of the sentence than the Spanish speakers did, which can illustrate some transfer.

\section{Conclusions}

Intonation plays an important role in language learning. This research has been focused on comparing intonation between native English speakers and ESL Spanish speakers. The results have shown significant differences, as well as similarities between the two languages. Individual differences were always taken into account, and the collected data has given an idea of the possible problems that Spanish speakers face when they learn English as a second language.

With the results previously mentioned, it is possible to conclude that similarities between languages were found. Similar intensity was found in the 
four sets of questions and, even though English speakers were louder than Spanish, this difference was not important. Pitch average and final rising intonation were shared basically in repetition, inverted, and tag questions. These results support Graham (1978) and Chela-Flores and Chela-Flores (2003) arguments related to intonation patterns in final rising contours.

Based on the results, it is possible to conclude that for the Spanish speakers participating in this study the pitch of wh-questions were the ones that obtained more different results in comparison to native English speakers, supporting Graham's (1978) claim.

To sum up, the outcomes of this research study have been useful to answer the research questions previously proposed. There are similarities between English and Spanish, but there are also significant differences that can be negatively transferred into the L2 giving support to what Bowen (1956) had previously stated. Individual differences are always present, and in order to have an idea without generalizing Spanish speakers, the average pattern was taken into account, rather than personal variations. The program Praat was used as a tool to measure similarities and differences among languages, because it generates clear and complete information.

The findings of this study concur with the previous literature discussed above. The results indicated that the participants shifted their intonation when it was needed, assuring that they have mastered the English language in terms of intonation patterns.

Since language performance depends basically on individual characteristics, visual and comparable feedback (English first language) help teachers to understand possible problems that their students face, and also helps to monitor their progress especially when they produce unclear sentences.

\section{Limitations}

This study had as a main objective to compare intonation between native English speakers and Spanish speakers (ESL). Even though it was possible to compare similarities and differences between languages, it is important to take into account the limitations that were present during the research. The number of participants was limited; however, generalized results were not the goal of this study. Females were not part of this study; participants were only males mainly because the contribution of females was difficult to obtain. 


\section{References}

BOERSMA, P.; WEENINK, D. Praat: Doing phonetics by computer (Version 5.0.40) [Computer program], 2008. Retrieved November 10, 2008, from $<$ http://www.praat.org $>$.

BOWEN, D. A comparison of the intonation patterns of English and Spanish. Hispania, v. 39, n. 1, p. 30-35, 1956.

CELCE-MURCIA, M.; BRINTON, D. M.; GOODWIN, J. Teaching pronunciation: A reference for teachers of English to speakers of other languages. Cambridge: Cambridge University Press, 1996.

CHELA-FLORES, B.; CHELA-FLORES, G. Intonation and sentence focus in English and Spanish: Implications for teaching. The Modern Language Society of Helsinki, v. 104, n. 3, p. 328-338, 2003.

ESCANDELL-VIDAL, V. Intonation and procedural encoding: The case of Spanish interrogatives. In: ROUCHOTA, V.; JUCKER, A. (eds.). Current Issues in Relevance Theory. Amsterdam: John Benjamins, 1998. p. 169-203.

FLEGE, J. A Critical Period for learning to Pronounce Foreign Languages?, Applied Linguistics, v. 8, p. 162, 1987.

GRAHAM, R. Intonation and emphasis in Spanish and English. Walled Lake, MI: Association of Teachers of Spanish and Portuguese, 1978.

JOHNS-LEWIS, C. Intonation in discourse. Houlton, ME: College-Hill Press, Inc., 1986.

LADEFOGED, P. Vowels and consonants: An introductory to sounds of languages. Oxford: Blackwell Publishing, 2001.

LADEFOGED, P. A course in phonetics. 5. ed. Oxford: Blackwell Publishing, 2006.

LEE, T. Laboratory approaches to Spanish phonology. Germany: Walter de Gruyter, 2004.

LEVIS, J. Intonation in theory and practice: Revisited. TESOL Quarterly, v. 33, n. 1, p. 37-63, 1999.

LINDH, J. Preliminary FO statistics and forensic phonetics. Proceedings, IAFPA, Department of Linguistics, Göteborg University, 2006.

RAMIREZ VERDUGO, D. The nature and patterning of native and non-native intonation in the expression of certainty and uncertainty: Pragmatic effects. Journal of Pragmatics, v. 37, p. 2086-1115, 2005.

RAMIREZ VERDUGO, D. A study of intonation awareness and learning in non-native speakers of English. Language Awareness, v. 15, n. 3, p. 141-159, 2006. 
SPAII, G.; HERMES, D. A visual display for the teaching of intonation. CALICO Journal, v. 10, n. 3, 1993.

WENNERSTROM, A. The music of everyday speech: Prosody and discourse analysis. New York: Oxford University Press, 2001. 


\section{Appendix}

\section{English questions}

1. Wh-questions

- What are you doing?

- Why is she crying?

- What can I do for you?

2. Tag questions

- It is a nice day, isn't it?

- People are worried about the economy, aren't they?

- The Dodgers won, didn't they?

3. Inverted questions

- John cooked dinner? ( focus on John)

- John cooked dinner? ( focus on dinner)

- John cooked dinner? (focus on cook)

4. Repetition questions

- What am I doing?

- What are you doing?

- You are doing what?

1. Wh-questions

Spanish questions

- ¿Cómo estás?

- ¿Porqué ella está llorando?

- ¿En qué puedo ayudarte?

2. Tag questions

- ¿Es un bonito día, cierto?

- ¿La gente está preocupada de la economía, cierto?

- ¿Los Dodgers ganraon, cierto?

3. Inverted questions

- ¿John preparó la cena? (enfasis en John)

- ¿John preparó la cena? (enfasis en cena)

- ¿John preparó la cena? (enfasis en preparó)

4. Repetition questions

- ¿Que tengo que hacer?

- ¿Que estás haciendo tú?

- ¿Estás haciendo que cosa?

Recebido em 12/01/2013. Aprovado em 16/09/2013. 